\title{
Quantification and Qualification Analysis of the Heat Waves Using Heat Wave Norm in the Region of Bechar (Algeria) during the Period 1951-2010
}

\author{
Miloud Oubadi1,2*, Ahmed Hamou1, Fantina Tidim ${ }^{3,4}$ \\ ${ }^{1}$ Laboratory of Environmental and Materials Sciences, Faculty of Exact \& Applied Sciences, Oran University 1-Ahmed Ben Bella, \\ Oran, Algeria \\ ${ }^{2}$ Scientific and Technical Research Center on Arid Regions, Biskra, Algeria \\ ${ }^{3}$ Department of Geography, Faculty of Letters, University of Porto, Porto, Portugal \\ ${ }^{4}$ Charles Darwin University, Darwin, Australia \\ Email: *oubadi@hotmail.fr
}

How to cite this paper: Oubadi, M., Hamou, A. and Tidim, F. (2020) Quantification and Qualification Analysis of the Heat Waves Using Heat Wave Norm in the Region of Bechar (Algeria) during the Period 1951-2010. Atmospheric and Climate Sciences, 10, 273-279.

https://doi.org/10.4236/acs.2020.103015

Received: March 22, 2020

Accepted: April 26, 2020

Published: April 29, 2020

Copyright $(02020$ by author(s) and Scientific Research Publishing Inc. This work is licensed under the Creative Commons Attribution International License (CC BY 4.0).

http://creativecommons.org/licenses/by/4.0/

\begin{abstract}
This study presents a new non-parametric measure of heat waves called heat wave norm (HWN), which allows quantifying and qualifying the magnitude of the summer heat wave events in the Bechar region located northwest of the Algerian Sahara over the period 1951-2010. The index, based on the analysis of daily maximum and minimum temperatures by adding them, integrated two dimensions at the same time: the duration and the excess heat. The results show an increase in the intensity and frequency of extreme events. More specifically, from the 1980s, it is possible to observe the propagation of extreme and very extreme and super extreme heat waves in recent decades with maximum presence during the period 1990-2010. In general, it can be said that the trend of excessive warming is clearly displayed in the Algerian Sahara, generally classified as a hot region.
\end{abstract}

\section{Keywords}

Algerian Sahara, Bechar, Excess Heat, Duration, Heat Wave, HWN

\section{Introduction}

Among extreme natural phenomena, heat waves constitute a worrying threat for the entire Mediterranean basin with more intensity in arid regions (South Shore). If, naturally, arid regions experience heat waves of all time, they become 
increasingly intense and spread over time and space. The adverse effects of these phenomena affect both natural resources: water, soil, vegetation, infrastructure and socio-economic activities and health [1] [2] [3]. These effects can be: 1) immediate or short-term, such as fires, lack of irrigation water or even potable water, crop losses or low yields, shortage of fodder for animals, loss of life; 2) or indirect or long-term, such as damage to infrastructure, change of vocation of territory, impacts on soils, forests and socio-economic activities (unemployment, rural exodus, decrease in investments, poverty...).

The trigger for international awareness took place after the unfortunate events of 2003, where in France alone, there were 15,000 deaths in 20 days [4]. The same year, a heat wave impacted Algeria in particular the Saharan region causing in Adrar 40 deaths; this heat wave was marked by its amplitude reaching $47^{\circ} \mathrm{C}$ and its duration spanned from June 21 to July 21 [5].

Heat waves are generally defined as extended periods of extreme heat; there is no consistent definition for the temperature threshold and the number of days used to define heat waves [6]. However, the temperature thresholds and the duration of the heat waves determine the dangerousness of the phenomenon [1] [7].

The indices measuring the extremes of hot temperature from the ETCCDI are used in numerous studies [8]-[16]. Other authors, without going through the ETCCDI indices, defined indices, for example, the Excess Heat Factor (EHF) defined by Nairn and Fawcett [17], the Heat Wave Magnitude Index daily (HWMId) proposed by Russo et al. [18], the Standardized Heat Index (SHI) developed by Raei et al. [19] and the heat index (HI) [20] defined by the National Weather Service/National Oceanic and Atmospheric Administration (NWS/NOAA). In this contribution, we propose a new non-parametric measure which combines duration and excessive heat in order to be able to define and classify heat waves. This index is called the Heat Wave Norm (HWN), and it is distinguished from other indexes by the fact that it gives the same weight to the two ingredients.

\section{Data and Methodology}

HWN is a new measure of the extent of heat waves, incorporating two dimensions. The first dimension is the duration of the heat wave. The second dimension is a measure of the excess heat during the heat wave period relative to a temperature threshold. In a plane related to the orthonormal reference $(O ; \vec{i}, \vec{j})$ (Figure 1), we consider the points $\mathrm{HW}_{i}\left(\mathrm{HWDI}_{i}, \mathrm{EH}_{i}\right)$ where $\mathrm{HWDI}_{i}$ is the index of the duration of the normalized heat wave, the normalization is done by the minimum duration of a heat wave which is 3 days and $\mathrm{EH}_{i}$ is the centered excess reduced heat after summing on each of the days of the heat wave. $\mathrm{HWN}_{i}$ is the distance between the origin and the point $\mathrm{HW}_{i}$ and calculated with the following formula:

$$
\mathrm{HWN}_{i}=\sqrt{\mathrm{HWDI}_{i}^{2}+\mathrm{EH}_{i}^{2}}
$$




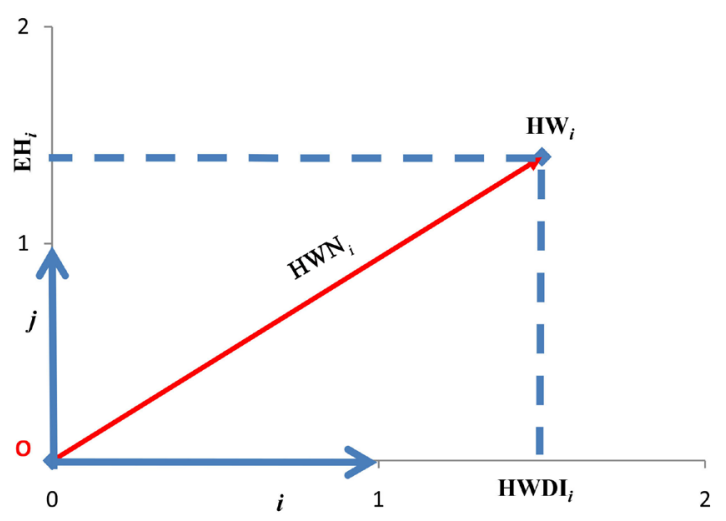

Figure 1. Illustration of the HWN calculation method by applying the Pythagorean Theorem "Equation (1)" where $\mathrm{HW}_{i}\left(\mathrm{HWDI}_{i} \mathrm{EH}_{i}\right)$ is a point in an orthonormal coordinate system and $\mathrm{HWN}_{i}$ (red line) is the distance between $\mathrm{HW}_{i}$ and the origin.

In our study we took into account both the maximum and the minimum of the day, not taking them individually but taking their sum which is fairly representative of the daily average temperature, since in summer, its evolution is close to a sinusoid [21].

We have chosen that a day is hot if the sum of the minimum $\left(\mathrm{T}_{\min }\right)$ and maximum $\left(\mathrm{T}_{\max }\right)$ temperatures exceeds the considered threshold, which is taken so that about $10 \%$ of the values are greater than it (Figure 2 ). The heat wave will be considered when three or more consecutive days exceed the previously mentioned temperature threshold.

We analyzed a series of minimum temperature $\left(\mathrm{T}_{\min }\right)$ and maximum temperature $\left(\mathrm{T}_{\max }\right)$ data for the hottest four months of the year (June, July, August and September), from 1951 to 2010. The choice from this period comes to the results of various studies on climate and global warming, for example, the work of [22] which clearly shows a break in stationarity towards the end of the 1970s.

To analyze the hot days, we used meteorological data from the National Office of Meteorology of Algeria [23]. The Bechar station (Latitude $31^{\circ} 38 \mathrm{~N}$ and Longitude $02^{\circ} 15 \mathrm{~W}$ ) is an arid region located in southwest Algeria (Figure 3).

\section{Results and Discussion}

We have classified heat waves according to the categories below:

Moderate $<2 \leq$ Severe $<4 \leq$ Extreme $<6 \leq$ Very extreme $<8 \leq$ Super extreme.

The heat wave was counted for the two separate periods (1951-1980) and (1981-2010) (Table 1). The number of moderate heat waves decreased from 41 cases for the first period to 32 cases for the second period, a decrease of more than $21 \%$, on the other hand, for the number of severe type heat waves is increased by $280 \%$. Heat waves during the first period (1951-1980) were limited to the moderate type $(\mathrm{HWN}<2)$ and severe $(\mathrm{HWN}<4)$ with much of the moderate type (98\%). It also appears that the appearance of severe heat waves multiplied by approximately 4 times during the second period (1981-2010) but the 


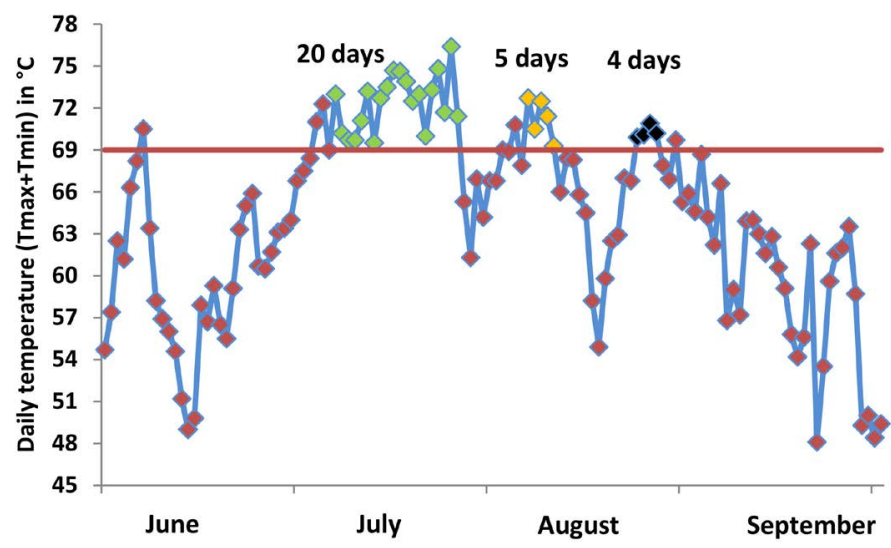

Figure 2. Illustration of the heat wave detection method for the summer season of 2010 where $\left(\mathrm{T}_{\max }+\mathrm{T}_{\min }\right)$ exceeds its 90 the quantile (the red line) calculated on 1951-2010. The green dots (yellow, black) represent the consecutive days constituting the heat waves.

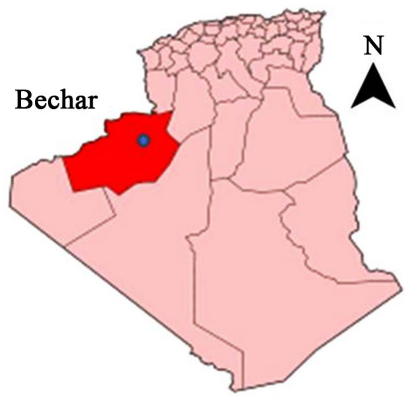

Figure 3. Location of the study area, the Bechar region, located in the southwest of Algeria.

Table 1. Number and categories of heat waves affected the region of Bechar during 1951-2010.

\begin{tabular}{ccccc}
\hline & Period & $1951-1980$ & $1981-2010$ & Total \\
\hline \multirow{3}{*}{ Class } & Moderate & 41 & 32 & 73 \\
& Severe & 5 & 19 & 24 \\
& Extreme & 0 & 3 & 3 \\
& Very extreme & 0 & 2 & 2 \\
& Super extreme & 0 & 1 & 1 \\
\hline
\end{tabular}

most characteristic of this last period is the appearance of the extreme type $(\mathrm{HWI}<6)$, very extreme $(\mathrm{HWN}<8)$ and super extreme $(\mathrm{HWN} \geq 8)$.

The number of heat waves has increased by more than $23 \%$ in the past 30 years with an increasing trend from the mid-1990s.

The highest number of heat waves was recorded in 1999, 2001, 2005 and 2010 this last year was exceptional (Figure 4).

The heat sequences have become longer and more frequent during the last two decades of the study period in phase with global warming. 


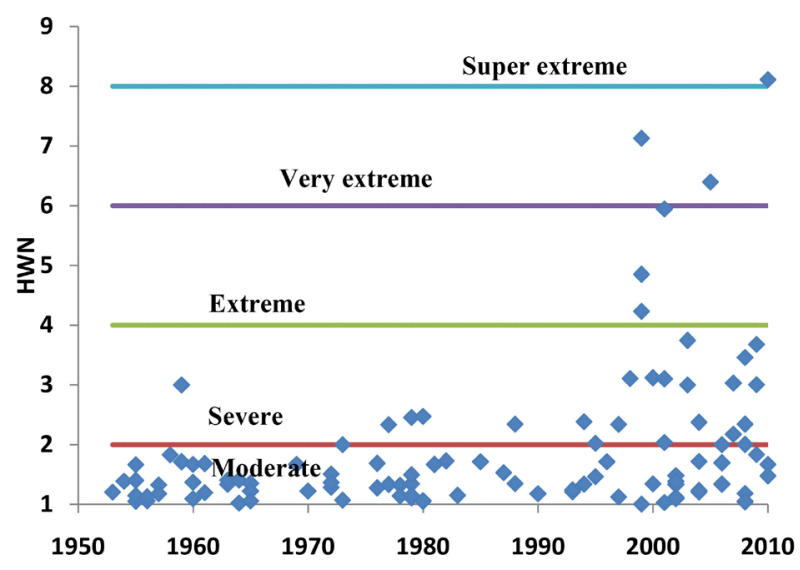

Figure 4. Categories of heat waves impacted the Bechar region during the periods 1951-2010. Moderate $<2 \leq$ Severe $<4 \leq$ Extreme $<6 \leq$ Very extreme $<8 \leq$ Super extreme.

\section{Conclusions}

In this work, we have developed a new climate index (HWN) that considers both the duration and the excessive heat of heat waves, allowing us to quantify and qualify the magnitude of heat waves.

The analysis of the minimum and maximum temperature data series from the Bechar meteorological station located in the Algerian Sahara over the period 1951-2010 clearly shows that from the beginning of the 1980s, the amplitude and the number of heat waves increased. This increase accelerated in the mid-90s. The results also show the appearance of extreme, very extreme and super extreme heat waves during the last decade, which gives a strong indication of the increase in the probability of occurrence of serious events in the years to come.

\section{Conflicts of Interest}

The authors declare no conflicts of interest regarding the publication of this paper.

\section{References}

[1] Gao, J., Sun, Y., et al. (2015) Impact of Extreme High Temperature on Mortality and Regional Level Definition of Heat Wave: A Multi-City Study in China. Science of the Total Environment, 505, 535-544. https://doi.org/10.1016/j.scitotenv.2014.10.028

[2] Mazdiyasni, O., AghaKouchak, A., et al. (2017) Increasing Probability of Mortality during Indian Heat Waves. Science Advances, 3, e1700066. https://doi.org/10.1126/sciadv.1700066

[3] Steffen, W., Hughes, L., et al. (2014) Heatwaves: Hotter, Longer, More Often. Climate Council of Australia.

[4] Kovats, R.S. and Hajat, S. (2008) Heat Stress and Public Health: A Critical Review. Annual Review of Public Health, 29, 41-55. https://doi.org/10.1146/annurev.publhealth.29.020907.090843

[5] EM-DAT (2020). International Disaster Database. Université Catholique de Louvain, 
Brussels.

[6] Anderson, G.B. and Bell, M.L. (2011) Heat Waves in the United States: Mortality Risk during Heat Waves and Effect Modification by Heat Wave Characteristics in 43 US Communities. Environmental Health Perspectives, 119, 210-218. https://doi.org/10.1289/ehp.1002313

[7] Shaposhnikov, D., Revich, B., et al. (2014) Mortality Related to Air Pollution with the Moscow Heat Wave and Wildfire of 2010. Epidemiology (Cambridge, Mass.), 25, 359. https://doi.org/10.1097/EDE.0000000000000090

[8] Aguilar, E., Aziz Barry, A., et al. (2009) Changes in Temperature and Precipitation Extremes in Western Central Africa, Guinea Conakry, and Zimbabwe, 1955-2006. Journal of Geophysical Research: Atmospheres, 114, D02115. https://doi.org/10.1029/2008JD011010

[9] Alexander, L.V. and Arblaster, J.M. (2009) Assessing Trends in Observed and Modelled Climate Extremes over Australia in Relation to Future Projections. International Journal of Climatology: A Journal of the Royal Meteorological Society, 29, 417-435. https://doi.org/10.1002/joc.1730

[10] Caesar, J., Alexander, L., et al. (2011) Changes in Temperature and Precipitation Extremes over the Indo-Pacific Region from 1971 to 2005. International Journal of Climatology, 31, 791-801. https://doi.org/10.1002/joc.2118

[11] Moron, V., Oueslati, B., et al. (2016) Trends of Mean Temperatures and Warm Extremes in Northern Tropical Africa (1961-2014) from Observed and PPCA-Reconstructed Time Series. Journal of Geophysical Research: Atmospheres, 121, 5298-5319. https://doi.org/10.1002/2015JD024303

[12] Peterson, T.C. and Manton, M.J. (2008) Monitoring Changes in Climate Extremes: A Tale of International Collaboration. Bulletin of the American Meteorological Society, 89, 1266-1271. https://doi.org/10.1175/2008BAMS2501.1

[13] Sillmann, J., Kharin, V.V., et al. (2013) Climate Extremes Indices in the CMIP5 Multimodel Ensemble: Part 2. Future Climate Projections. Journal of Geophysical Research: Atmospheres, 118, 2473-2493. https://doi.org/10.1002/jgrd.50188

[14] Vincent, L., Aguilar, E., et al. (2011) Observed Trends in Indices of Daily and Extreme Temperature and Precipitation for the Countries of the Western Indian Ocean, 1961-2008. Journal of Geophysical Research: Atmospheres, 116, D10108. https://doi.org/10.1029/2010JD015303

[15] You, Q., Kang, S., et al. (2011) Changes in Daily Climate Extremes in China and Their Connection to the Large Scale Atmospheric Circulation during 1961-2003. Climate Dynamics, 36, 2399-2417. https://doi.org/10.1007/s00382-009-0735-0

[16] Zhang, X., Alexander, L., et al. (2011) Indices for Monitoring Changes in Extremes Based on Daily Temperature and Precipitation Data. Wiley Interdisciplinary Reviews. Climate Change, 2, 851-870. https://doi.org/10.1002/wcc.147

[17] Nairn, J.R. and Fawcett, R.J. (2015) The Excess Heat Factor: A Metric for Heatwave Intensity and Its Use in Classifying Heatwave Severity. International Journal of Environmental Research and Public Health, 12, 227-253.

https://doi.org/10.3390/ijerph120100227

[18] Russo, S., Sillmann, J., et al. (2015) Top Ten European Heatwaves since 1950 and Their Occurrence in the Coming Decades. Environmental Research Letters, 10, Article ID: 124003. https://doi.org/10.1088/1748-9326/10/12/124003

[19] Raei, E., Nikoo, M.R., et al. (2018) GHWR, a Multi-Method Global Heatwave and Warm-Spell Record and Toolbox. Scientific Data, 5, 1-15.

https://doi.org/10.1038/sdata.2018.206 
[20] Oueslati, B., Pohl, B., et al. (2017) Characterization of Heat Waves in the Sahel and Associated Physical Mechanisms. Journal of Climate, 30, 3095-3115. https://doi.org/10.1175/JCLI-D-16-0432.1

[21] Faci, M., Matari, A., Oubadi, M., Boudjemline, F. and Farhi, Y. (2016) Analyse des journées de forte chaleur à l'Ouest Algérien.

[22] Belarbi, H., Matari, A., et al. (2012) Etude des séries temporelles: Application aux données hydroclimatiques. Editions Universitaires Européennes EUE (Allemagne).

[23] NMO (2010) National Meteorological Office. Algeria. 